\title{
A CECUEIRA, OS COMPUTADORES E ESTRATÉGIAS PARA INCLUSÃO ESCOLAR
}

\author{
THE BLINDNESS, THE COMPUTERS AND \\ STRATEGIES FOR SCHOLAR INCLUSION
}

Vladimir Figueiredo Fraga vladimir.fraga@gmail.com

Mestre em Diversidade Cultural e Inclusão Social pela Universidade Feevale (Novo Hamburgo/Brasil).

\section{Regina de Oliveira Heidrich Correio rheidrich@feevale.br}

Doutora em Informática na Educação pela Universidade Federal do Rio Grande do Sul (Porto Alegre/Brasil).

Professora na Universidade Feevale (Novo Hamburgo/Brasil). 


\section{RESUMO}

Ainclusão depessoa cega em disciplinas de infraestrutura tecnológica, noensinotécnico profissionalizante, envolve o agenciamento de uma variedade de recursos utilizados também no mercado de trabalho. 0 processo de ensino/aprendizagem neste contexto estará, em parte, limitado por quanto acessíveis forem estes recursos. Para que a referida inclusão efetive-se, mesmo na ausência de tecnologia acessível, pode ser necessária a utilização de estratégias pedagógicas, e descrevê-las é o objetivo desse trabalho, assim como propostas para produção de tecnologia mais acessível. A existência de atividades que envolvam algum tipo de risco também deve ser considerada, assim como adaptações curriculares e definição de atividades individuais ou em grupo, em contexto de sala de aula e laboratório. Como metodologia é utilizada uma reflexão teórica sobre prática docente realizada através de estudo de caso descritivo. Como conclusão tem-se uma série de considerações para o aperfeiçoamento dos recursos e das estratégias pedagógicas, envolvendo a inclusão escolar de pessoas cegas em cursos de infraestrutura tecnológica de informática no sistema comum de educação.

Palavras-chave: Educação. Inclusão. Estratégias. Tecnologias. Recursos.

\section{ABSTRACT}

The inclusion of blind people in disciplines of technological infrastructure, in vocational technical education, involves the handling of a variety of resources which are also used in the labor market. The teaching/learning process in this context will be limited in part by how accessible these resources are. For such inclusion to be effective, even in the absence of accessible technology, it may be necessary to use pedagogical strategies, to describe them is the objective of this work, as well as proposals for the production of more accessible technology. The existence of activities that involves some type of risk should be considered also, as well as curricular adaptations and definition of individual or group activities, in the context of classroom and laboratory. As methodology is used a theoretical reflection on teaching practice carried out through a descriptive case study. As a conclusion, there are a number of considerations for the improvement of resources and pedagogical strategies involving the inclusion of blind people in educational courses of IT infrastructure in the common education system.

Keywords: Education. Inclusion. Strategies. Technologies. Resources. 


\section{INTRODUÇão}

A inclusão de pessoas com deficiências nas instituições de ensino e no mercado de trabalho encontra-se em situação de aperfeiçoamento. Por um longo período na história, as pessoas com deficiências estiveram à margem do sistema de ensino formal e do mercado de trabalho. Com a criação de instituições especializadas, que recebem as pessoas com deficiências, fornecendo alguma forma de ensino e trabalho, por vezes restritas e limitadas, teve início o modelo de separação, ou segregação. Considerando o modelo de integração, mais recente, a pessoa com deficiência frequenta as mesmas escolas que os demais estudantes, porém, realizando atividades diferentes, ou seja, encontram-se frequentando a mesma instituição, mas trabalhando em atividades separadas, em salas diferentes ou com professores diferentes. A interação entre alunos comuns e alunos com deficiências no modelo de integração torna-se existente, mas limitada. Com a proposta e implementação do modelo de inclusão, objetiva-se garantir que pessoas com deficiências frequentem instituições de ensino comuns, realizando as mesmas atividades, no mesmo local, ao mesmo tempo e com o mesmo professor. A justificativa para esta proposta relaciona-se com as novas interações sociais proporcionadas, com potencial para resultarem em ganhos no processo de ensino/aprendizagem de todos, através da socialização da pessoa com deficiência.

O modelo de inclusão tem sido defendido como o modelo mais benéfico para os estudantes e para a sociedade em geral, e diversas estratégias têm sido elaboradas para tornar o modelo de inclusão o modelo padrão em nossa sociedade. Descrever este conjunto de estratégias representa o objetivo desse artigo, assim como propostas para o aperfeiçoamento dos recursos, visando promover a inclusão da pessoa cega em cursos de infraestrutura tecnológica. 0 seguinte referencial foi considerado para esse trabalho:

- O referencial teórico para o modelo de inclusão em estudo utiliza os Paradigmas do Sistema Escolar propostos por Beyer (Figura 1) e de interações sociais proposto por Vygotsky (apud Oliveira, 1997, p. 60), que atribui grande importância às referidas interações para o processo de construção das funções psicológicas do ser humano. Vygotsky considera que o desenvolvimento individual ocorre em um ambiente social determinado através da relação com o outro e considera que este é essencial para o processo de construção psicológica. 
Figura 1 - Paradigmas do Sistema Escolar

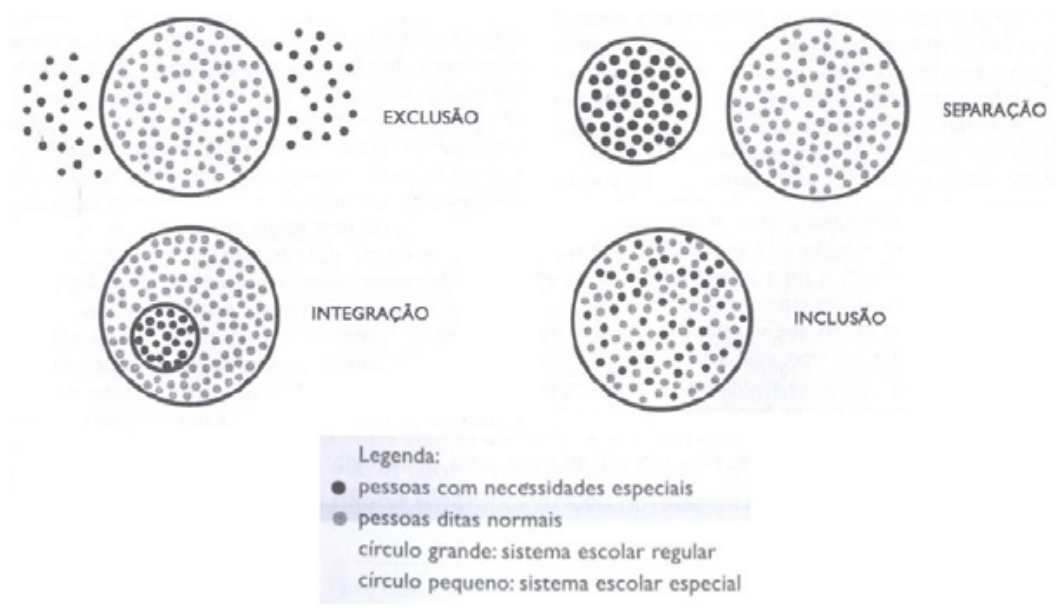

Fonte: Beyer (2006, p. 76)

- Em consonância com os Paradigmas do Sistema Escolar de Beyer, os modelos de barreiras propostos por Augustin também fazem parte do referencial teórico. Neste modelo a pessoa com deficiência é identificada como desafiada por três barreiras: de acessibilidade, institucional e atitudinais, sendo que: "[...] acredita-se que superando estas barreiras haverá um impacto benéfico para toda a comunidade." (AUGUSTIN, 2012, p. 3). Este modelo, denominado Modelo Social, leva à compreensão de que o problema não está na pessoa ou em sua deficiência, mas que a deficiência assume uma dimensão social que leva à exclusão.

- O Capítulo IV, Do Direito à Educação, da lei 13.146 de julho de 2015, coloca a inclusão plena como objetivo a ser alcançado, incumbindo ao Poder Público "[...] sistema educacional inclusivo em todos os niveis e modalidades, bem como o aprendizado ao longo de toda a vida [...]" (BRASIL, 2015) e "[...] acesso à educação superior e à educação profissional e tecnológica em igualdade de oportunidades e condições com as demais pessoas [...]" (BRASIL, 2015, grifo do autor).

- A lei 13.146, em seu parágrafo primeiro, estabelece avaliação e restrição de participação.

[...] A avaliação da deficiência, quando necessária, será biopsicossocial, realizada por equipe multiprofissional e interdisciplinar e considerará: I - os impedimentos nas funções e nas estruturas do corpo; II - os fatores socioambientais, psicológicos e pessoais; III - a limitação no desempenho de atividades; e IV - a restrição de participaçãa. [...] (BRASIL, 2015). 
- A Convenção sobre os Direitos das Pessoas com Deficiência (CDPD), da Organização das Nações Unidas (ONU), adota a regra do reconhecimento igual perante a lei, devendo ser asseguradas às pessoas com deficiência medidas adequadas para o exercício da capacidade legal. Somente quando necessário é que a capacidade legal (civil) da pessoa poderá ser limitada. Nesse caso, todos os apoios e salvaguardas apropriadas e efetivas deverão ser disponibilizadas para a proteção do direito, da vontade e da autonomia da pessoa, conforme Brasil (2014, p. 5, grifo do autor).

- A tecnologia envolvendo o processo de ensino/aprendizagem em disciplinas de redes de computadores é a mesma tecnologia utilizada no mercado de trabalho, sendo que toda a tecnologia deve respeitar as normas de acessibilidade para que os direitos das pessoas com deficiências sejam atendidos em "[...] igualdade de oportunidades e condições [...]" (BRASIL, 2015).

\section{METODOLOGIA}

O presente artigo foi construído a partir de uma reflexão teórica sobre prática docente realizada através de estudo de caso descritivo, desenvolvido em uma situação natural (naturalística), na modalidade qualitativa, considerando inclusão de pessoa cega nas disciplinas Arquitetura e Redes de Computadores I e Arquitetura e Redes de Computadores II, em turmas com 18 e 19 discentes. Ambas as disciplinas fazem parte de um curso técnico de informática noturno com dois anos de duração, em escola técnica do sistema comum de educação, no estado do Rio Grande do Sul.

As referidas disciplinas são divididas em aulas para fundamentação teórica do conteúdo curricular, e em aulas compostas por atividades práticas, objetivando a formação de auxiliares técnicos em redes de computadores. A coleta de dados foi realizada através de observação participativa do processo de ensino/aprendizagem e da correção de avaliações somativas e diagnósticas, por dois semestres no total. A avaliação da acessibilidade dos recursos foi realizada através do teste, para acessibilidade, de todos os dispositivos de redes de computadores, dos programas utilitários e dos sistemas operacionais utilizados nas aulas práticas. As ferramentas foram verificadas em busca de informações em Braille e proteção a partes perfurantes/cortantes, assim como à superfície externa de todo hardware. Como resultado, temse um conjunto de reflexões e propostas para o aperfeiçoamento do processo de ensino/aprendizagem e dos recursos utilizados em contexto tecnológico profissionalizante.

\section{CONTEXTUALIZAÇÃO: USUÁRIO E TÉCNICO dE INFORMática}

Antes de relatar sobre as estratégias pedagógicas para inclusão de pessoas cegas nas instituições de ensino comuns, é necessário estabelecer uma base conceitual, sendo que esta base é dependente do tipo de 
deficiência e daárea em que o modelo de inclusão está sendo aplicado. Portanto, torna-se necessário trabalhar as especificidades do contexto em que a inclusão está sendo implementada e, para isto, é pertinente uma breve descrição sobre os recursos utilizados em contexto tecnológico e profissionalizante, mais especificamente na área da informática e redes de computadores, e considerando a inclusão de pessoa cega.

0 processo de ensino/aprendizagem de informática pode ser voltado a tornar uma pessoa um usuário ou um técnico. Para um usuário de computadores e redes de computadores, as atividades envolvem a editoração de documentos, cópia, recorte e colagem de arquivos, utilização da Internet para navegar em Websites, envio de mensagens por E-mail e até mesmo instalação/desinstalação simples de programas, de impressoras e de scanners. Já o técnico de informática é responsável por preparar computadores para serem utilizados por usuários e por vezes isto inclui a preparação do computador para funcionar em rede, tendo em vista que a tecnologia de redes de computadores serve como base para o compartilhamento de recursos e para o acesso à Internet.

Não existe divisão formal entre as atividades que um usuário de informática executa e as atividades que um técnico de informática executa, sendo que existem usuários capazes de realizarem atividades de técnicos sem nunca terem realizado cursos para este fim. A diferenciação entre um usuário de informática e um técnico de informática também não é formal nos sistemas operacionais, sendo que em tais sistemas existem seções para a utilização (ex.: Área de Trabalho no Microsoft Windows) e para configuração (ex.: Painel de Controle, também no Microsoft Windows). A referida diferenciação, entretanto, é pertinente, pois atualmente as seções utilizadas pelo usuário e pelo técnico variam quanto à acessibilidade por programas leitores de tela.

Portanto, em relação a tornar-se um técnico de informática, existe um conjunto de conhecimentos teóricos e de habilidades práticas que são significativamente diferentes dos exigidos de um usuário de informática e que precisam ser considerados, pois este diferente conjunto de conhecimentos e habilidades envolve um conjunto diferente de recursos tecnológicos. Para o técnico de informática, mais especificamente, para o técnico de redes de computadores, por exemplo, são necessários Hubs, Switches, Pontos de Acesso e Roteadores de Banda Larga construídos de acordo com as normas de acessibilidade para pessoas cegas. Dependendo da responsabilidade do técnico, podem ser necessárias ferramentas, dispositivos de aferição e insumos considerando a manipulação por técnicos cegos. Entre os requisitos, alguns deles são: embalagens com informações em Braille, manuais em Braille ou compatíveis com programas leitores de tela, interfaces externas com indicações em Braille, feedback sonoro para sinais luminosos, interface externa com instruções em relevo utilizando Braille e interfaces de configuração também compativeis com programas leitores de tela. 
As seções de configuração dos sistemas operacionais e os programas utilitários também precisam ser construídas respeitando as normas de acessibilidade. Logo, o conjunto de recursos tecnológicos necessários para ser um técnico cego é significativamente diferente do conjunto de recursos tecnológicos necessários para ser um usuário cego.

Atualmente a legislação garante acesso para pessoas cegas a cursos técnicos profissionalizantes de informática, alguns com disciplinas de infraestrutura tecnológica de redes de computadores, sendo que, usualmente, as aulas de cursos tecnológicos envolvem dois tipos de atividades: apreensão da fundamentação teórica e aquisição de um conjunto de habilidades práticas. Tais habilidades práticas são adquiridas através de aulas que envolvem a manipulação dos recursos necessários para ser um técnico, sendo que quando tais recursos não são planejados considerando a manipulação por pessoas cegas existem alternativas sobre como conduzir o processo de ensino/aprendizagem. Relatar sobre estas alternativas é o objetivo desse trabalho, assim como avaliar a acessibilidade dos recursos e propor soluções para produção de tecnologia mais acessível através do aprimoramento das políticas públicas.

\section{RESULTADOS}

Considerando os resultados das disciplinas em estudo, a aluna foi aprovada em Arquitetura e Redes de Computadores I, demonstrando compreensão da fundamentação teórica, porém não realizando a montagem de cabeamento de rede e a configuração de Roteador de Banda Larga residencial, por motivo de hardware e software não acessíveis. Não foram observadas dificuldades significativas considerando a apropriação da fundamentação teórica, sendo que a condição específica da aluna (cegueira) não foi fator incapacitante.

A aluna também foi aprovada na disciplina Arquitetura e Redes de Computadores II, depois de avaliado, pelo professor, que o hardware e software à disposição não foram construídos de maneira acessível para estudantes submetidos ao processo de ensino/aprendizagem para tornarem-se técnicos de informática cegos. As dificuldades envolvendo a execução das atividades práticas foram significativas, sendo que a condição específica da aluna foi fator incapacitante para a não realização da maior parte das atividades práticas de maneira autônoma.

Com base na observação participativa e nos resultados de avaliações diagnósticas e somativas, o estudo de caso permite a reflexão sobre determinados aspectos do processo de ensino/aprendizagem da pessoa cega no sistema comum de educação tecnológica profissionalizante. Estes aspectos podem ser divididos em categorias, sendo estas: Fundamentação Teórica Curricular, Atividades Práticas, Atividades em Grupo, Adaptação dos Recursos e Atividades Diferenciadas como Resultados de Adaptações 
Curriculares. A seguir, são apresentadas reflexões sobre cada uma destas categorias, assim como propostas para o aprimoramento de recursos, entre outras questões, em âmbito de Considerações Finais.

\subsection{FUNDAMENTAÇÃO TEÓRICA CURRICULAR}

Considerando o lecionar de conteúdo teórico de informática e de redes de computadores, as aulas envolvem a descrição de conceitos sobre a tecnologia de informática em formato textual, em formato diagramático e em formato de imagens. Descrições teóricas sobre os softwares e hardwares utilizados fornecem a base para um entendimento sobre as funções dos equipamentos e dos protocolos. Entre as atividades envolvidas para o lecionar deste conteúdo estão as aulas expositivas, quando o professor através da utilização da fala - explica sobre a função e as características de cada equipamento e protocolo, também utilizando material em formato textual, em formato de diagrama e em formato de imagens. Considerando a inclusão de pessoa cega neste tipo de aula, são necessários arquivos textos fornecidos em formato compatível com programas leitores de tela, diagramas em relevo e descrição textual das imagens. Também é necessária a configuração de computador para permitir que a pessoa cega o utilize para leitura do material, e para troca de mensagens com colegas e professor, quando utilizado o sistema de Educação a Distância (EAD).

O sistema Braille de escrita e leitura é essencial, possibilitando que através dele sejam feitas conexões entre o material em formato diagramático e instruções complementares sobre os diagramas sendo fornecidos em arquivo texto compativel com programas leitores de tela, utilizando mídia portátil. Na Figura 2, temos uma questão teórica em relevo, utilizando Braille. A questão deveria ser respondida em um computador com programa leitor de telas, em arquivo texto contendo também detalhes sobre a questão a resolver, fornecida através de arquivo digital compatível com aplicativo editor de textos e programa leitor de telas. 


\section{CONHECIMENTO

Figura 2 - Questão Teórica em Diagrama em Relevo com Braille

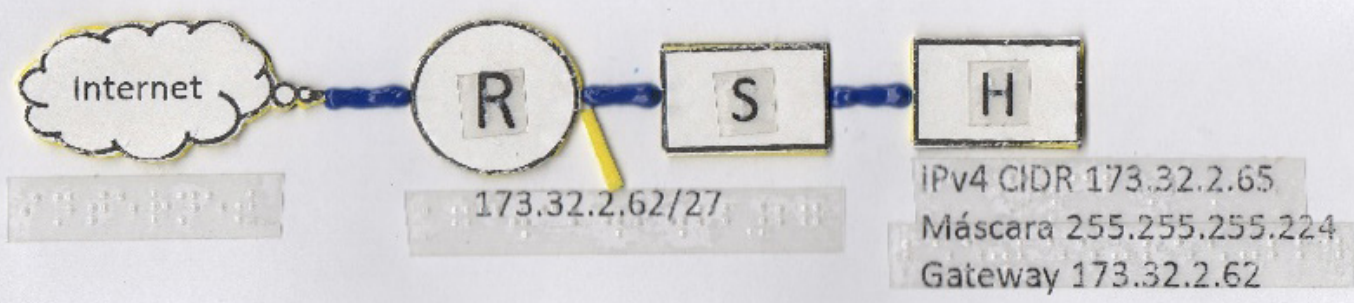

Questãc

onde esta 0 erro no diagrama acima e como corrigir?

\section{Fonte: capturado pelo autor}

Os recursos utilizados para a fundamentação teórica, portanto, são os seguintes:

- Computador com programa leitor de telas.

- Material em formato textual compatível com programa leitor de telas.

- Descrição textual das imagens.

- Diagramas em relevo.

- Material impresso no sistema Braille.

- Descrição linear de tabelas e fluxogramas.

Com a inclusão de pessoa cega em aulas teóricas de infraestrutura tecnológica, estes recursos são suficientes para o lecionar da fundamentação teórica, podendo-se afirmar que a única diferença é o tempo adicional para preparação de material adaptado, para configuração de computador, e uma modificação no ritmo das aulas para possibilitar que a informação seja apreendida dentro de uma determinada quantidade de tempo, mais dependente de uma sequência temporal. Esta diferença entre a maneira da pessoa cega apreender determinada quantidade de informações pode ser denominada especificidade, sendo que as aulas devem ser planejadas de acordo com esta especificidade.

[...] A especificidade reside no tipo de material a ser utilizado, bem como em algumas estratégias de organização da situação de ensino. Nesse caso, o uso preferencial do tato, do ouvido e do olfato para estabelecer relações com o meio propicia um desenvolvimento diferenciado das competências perceptivas e cognitivas. A capacidade de perceber objetos, meio e pessoas é construída a partir desses sentidos que se caracterizam por organizar a informação em séries temporais, em que um dado se apresenta após o outro, 
na forma de uma sequência. A integração desses dados num todo único (o objeto) ocorre de maneira fundamentalmente diferente daquela propiciada pela visão, cujo traço mais marcante é a simultaneidade [...] (OCHAITA; ROSA, 1995; BATISTA; ENUMO, 2000, apud LAPLANE; BATISTA, 2012, p. 181-182).

Tendo em vista os recursos institucionais à disposição para os docentes utilizarem no processo de ensino/aprendizagem em turmas compostas por pessoa cega, encontra-se computador com programa de leitura de telas (e material compativel), etiquetadora Braille, impressora Braille, materiais para produção manual de diagramas em relevo, além de máquinas para produção e reprodução de materiais em relevo. Considerando a existência de todos estes recursos, as aulas estarão apenas limitadas pela velocidade da apreensão das informações adquiridas através de vias mais sequenciais, que demandam uma quantidade maior de tempo do que a via visual. Portanto, a condição específica da aluna (cegueira) não é fator incapacitante quando considerado o processo de ensino/aprendizagem de conteúdo teórico.

\subsection{ATIVIDADES PRÁTICAS}

Considerando as atividades práticas que envolvem a manipulação de hardware e software para intervenções no ambiente através da configuração de programas e dispositivos, as atividades estarão limitadas a quanto acessível for a tecnologia. Em uma situação na qual todos os equipamentos e programas de computador à disposição forem construídos de acordo com as regras de acessibilidade para pessoas cegas, o fator mais importante a considerar para o desenvolvimento de atividades práticas é o fator tempo. Por motivo da aquisição de informações por parte de uma pessoa cega ser mais dependente de uma dimensão temporal, pode ser necessário mais tempo para condução da mesma atividade. Os programas leitores de tela funcionam de maneira sequencial e, se a configuração a ser alterada não se encontrar no início do arquivo, pode ser necessário ler todas as opções até que seja encontrada a informação a ser alterada. Quando se deseja passar para a próxima opção, podem ser necessários comandos para que a informação seguinte seja sintetizada em áudio pelo programa leitor de telas. Na Figura 3 tem-se uma atividade prática com recursos parcialmente acessíveis e envolvendo periculosidade. 
Figura 3 - Recursos para Aula Prática

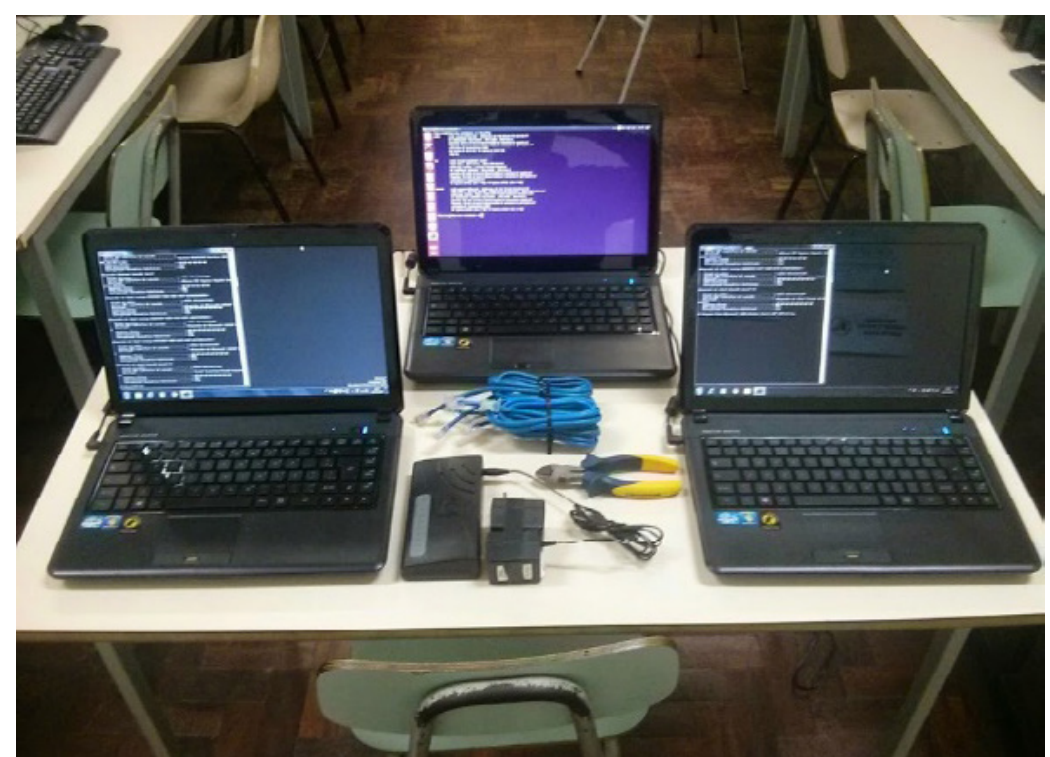

Fonte: capturado pelo autor

O manusear de equipamento que contenha informações em relevo no formato Braille em sua interface externa também pode depender de uma quantidade de tempo maior do que através da identificação das informações visuais presentes no mesmo equipamento, devido à necessidade do contato físico em partes do equipamento até que a informação em interesse seja encontrada. Portanto, considerando que a tecnologia esteja de acordo com as normas de acessibilidade, não existem impedimentos para execução das atividades de maneira individual e autônoma, entretanto, as aulas devem ser planejadas considerando a diferente velocidade para aquisição das informações. Logo, considerando que todos os recursos tecnológicos sejam acessíveis, a condição específica da aluna (cegueira) não é fator incapacitante.

Quando a tecnologia não se encontra de acordo com as normas de acessibilidade, as atividades práticas não podem ser executadas de maneira autônoma e individual pela pessoa cega. Nestes casos, a utilização de atividades individuais ainda pode ser útil, para quando for necessário estipular os motivos pelos quais tais atividades não puderam ser realizadas, objetivando a tomada de conhecimento sobre quais recursos precisam ser aperfeiçoados. Esta coleta de dados também pode ser utilizada para justificar a restrição de participação, assim como previsto em lei, e gerar uma base de conhecimentos para que providências, objetivando um aperfeiçoamento dos recursos, sejam consideradas. A realização 
de avaliações formativas e diagnósticas, assim como a observação participativa, de atividades individuais, mesmo com a utilização de recursos fora das normas de acessibilidade, permite, portanto, um feedback para o aperfeiçoamento dos recursos, para restrição de participação ou para utilização de atividades adaptadas através das adaptações curriculares.

Quando a situação ideal de ter todos os equipamentos e programas construídos de acordo com regras de acessibilidade não estiver presente, existem um conjunto de opções que permitem que as aulas sejam conduzidas de maneira a considerar a aplicação do modelo de inclusão e, ao mesmo tempo, permitir que algumas atividades práticas sejam executadas. Entretanto, estas opções podem não ser passíveis de repetição em um ambiente profissional em que o professor, os mesmos recursos e os mesmos alunos não estarão presentes. As seguintes opções apresentam-se quando consideramos a inclusão de pessoa cega em aulas práticas do sistema comum de educação profissionalizante de infraestrutura tecnológica e que envolvem a utilização de tecnologia não acessível:

- Atividades em grupo.

- Adaptação de recursos em laboratório.

- Atividades diferenciadas (adaptações curriculares).

\subsection{ATIVIDADES EM GRUPO}

A importância das atividades em grupo para o desenvolvimento do ser humano através das interações sociais é relevante, e sua utilização como parte do processo de ensino/aprendizagem é amplamente implementada entre profissionais da educação. Com o aperfeiçoamento da tecnologia de informática, atividades em grupo também podem ser realizadas a distância. Atitudes colaborativas e competências sociais são estimuladas nas atividades em grupo, assim como a troca de conhecimentos, relações de amizade e solidariedade.

[...] a escola promove uma variedade de relações interpessoais cuja importância está em promover a formação e desenvolvimento das funções psicológicas caracteristicamente humanas. [...] Essas interações que 0 indivíduo estabelece com as pessoas que 0 cercam, seja na escola ou em outro ambiente, exercem, portanto, papel fundamental no desenvolvimento humano, pois é a partir da apropriação das significações socialmente produzidas que as funções psicológicas se constituem, o que vem ressaltar a gênese social da consciência humana defendida por Vygotsky (ZANELLA, 2001, p. 96).

A atividade em grupo, entretanto, quando utilizada por motivo de ausência de recursos acessíveis, além de não colaborar para o aperfeiçoamento dos recursos, tem potencial para perpetuar um conjunto 


\section{CONHECIMENTO

de práticas pedagógicas que não contribuem para tornar a pessoa com deficiência mais autônoma. Atividades em grupo, sejam presenciais, sejam a distância, devem ser realizadas por seus próprios méritos, e não como subterfúgio para recursos que não consideram pessoas cegas em sua utilização. $A$ problemática torna-se mais importante quando considerado o contexto profissionalizante, situação na qual a mesma tecnologia que é utilizada em sala de aula e laboratório é utilizada no mercado de trabalho.

A pessoa cega, nas atividades em grupo que utilizam recursos inacessíveis, não estará nas mesmas condições de igualdade para efetuar contribuições, quando em comparação com seus colegas, e seu desempenho estará limitado pela qualidade do material adaptado, pela articulação linguística dos colegas e pela vontade destes de atuarem de maneira colaborativa, ou seja, a pessoa cega estará limitada por condições estritamente dependentes dos demais membros do grupo. Entretanto, a atividade em grupo, quando colaborativa, permite que a pessoa cega faça contribuições em termos teóricos, ou seja, sobre os conhecimentos necessários para configurar determinado dispositivo, utilizando seus colegas como intermediários entre a intervenção prática em si (o manipular da tecnologia) e os conhecimentos teóricos para realizar sua configuração (procedimentos e comandos a serem executados). A atividade em grupo, portanto, tem potencial para promover uma série de interações sociais para a construção de um ambiente mais solidário e colaborativo em âmbito de sala de aula e laboratório, porém, questões relacionadas com procedimentos que envolvam riscos, como o manipular de ferramentas e material energizado, devem ser consideradas, e para isto, o professor deve estar atento para garantir a segurança dos estudantes. Logo, estabelecer atividades em grupo, do ponto de vista do professor, envolve riscos consideráveis, já que o mesmo é responsável por promover práticas pedagógicas seguras.

A preparação de material adaptado por parte dos estudantes é uma opção, porém, o material adaptado tem potencial para não ser útil por não atender todos os requisitos de acessibilidade, afinal, nem todos os estudantes foram instruídos sobre como preparar este tipo de material, o que pode resultar em material fora de conformidade pedagógica ou mesmo com erros em termos de conteúdos específicos. A decisão do professor de lecionar estes tipos de competências e habilidades é uma opção, porém, com provável impacto no tempo disponível para o lecionar de conteúdo curricular obrigatório. Em outras palavras: não existem soluções sem custos e riscos, e mesmo quando todos recursos tecnológicos são acessíveis, deve ser considerada a velocidade diferenciada para a execução das atividades.

\subsection{ADAPTAÇÃO DOS RECURSOS}

Umas das possibilidades para execução de atividades práticas de maneira independente e autônoma nas aulas práticas é através da adaptação das tecnologias que serão utilizadas no processo de ensino/ 
aprendizagem. Um exemplo desta adaptação é colar etiquetas com informações em Braille na interface externa dos equipamentos. Outra adaptação possivel, porém, de complexa realização, envolve a substituição da interface de configuração do dispositivo (o software) por uma versão acessivel da mesma interface, criada para funcionar em conjunto com programas leitores de tela. Realizar tal adaptação envolve alteração de software e é uma tarefa que poucas instituições são capazes de realizar por requisitarem um enorme e complexo conjunto de competências técnicas, usualmente de responsabilidade de profissionais especializados.

A adaptação de recursos para serem utilizados somente em laboratório, mesmo que fosse passível de ser inteiramente realizada, não soluciona a problemática da inclusão em ambiente profissional, já que as mesmas adaptações não estarão presentes na tecnologia utilizada no mercado de trabalho. A realização de atividades práticas com potencial para risco, por exemplo, nas situações em que são necessárias a utilização de ferramentas (ex.: alicates cortantes e crimpadores) envolvem riscos quando a ferramenta não é construída para ser utilizada por uma pessoa cega. A realização de atividades em grupo com a utilização de tais ferramentas, considerando as interações entre os alunos, resulta em uma dinâmica mais complexa de ser observada por parte do professor, sendo que são aumentadas as dificuldades de intervenção objetivando assegurar a segurança física dos estudantes.

\subsection{ATIVIDADES DIFERENCIADAS COMO RESULTADOS DE ADAPTAÇÕES CURRICULARES}

Atividades diferenciadas sendo executadas como implementação de Adaptações Curriculares (AC) podem ser uma opção quando a tecnologia é inacessível. A pessoa cega, neste caso, não realizaria a atividade envolvendo manipulação direta da tecnologia, quando esta for inacessível, executando em seu lugar atividade diferente dos demais estudantes. Obviamente que esta estratégia resulta em algum grau de integração (nem todos estudantes estarão envolvidos nas mesmas atividades, apesar de estarem no mesmo local) dentro de um ambiente em que a inclusão foi fixada como objetivo a ser atingido.

As AC consistem em modificações espontaneamente realizadas pelos professores e, também, em todas as estratégias que são intencionalmente organizadas para dar respostas às necessidades de cada aluno, particularmente dos que apresentam dificuldades de aprendizagem. [...] De início cumpre evidenciar que as AC devem ser entendidas como mais um instrumento que possibilita maiores niveis de individualização do processo ensino-aprendizagem escolares, particularmente importante para alunos que apresentam necessidades educacionais especiais (CARVALHO, 2014, p. 103).

Atividades diferenciadas, implementadas como resultado de adaptações curriculares, podem resultar em uma elevação da complexidade no planejamento das aulas, sendo que o professor terá que 
planejar mais de uma atividade para a mesma aula. Na Figura 4, tem-se em andamento uma avaliação adaptada para aluna cega e avaliação comum para os demais estudantes. Na seção à direita da sala, estão dispostos os recursos para avaliação prática a ser realizada após avaliação teórica.

Figura 4 - Avaliação Adaptada e Avaliação Comum

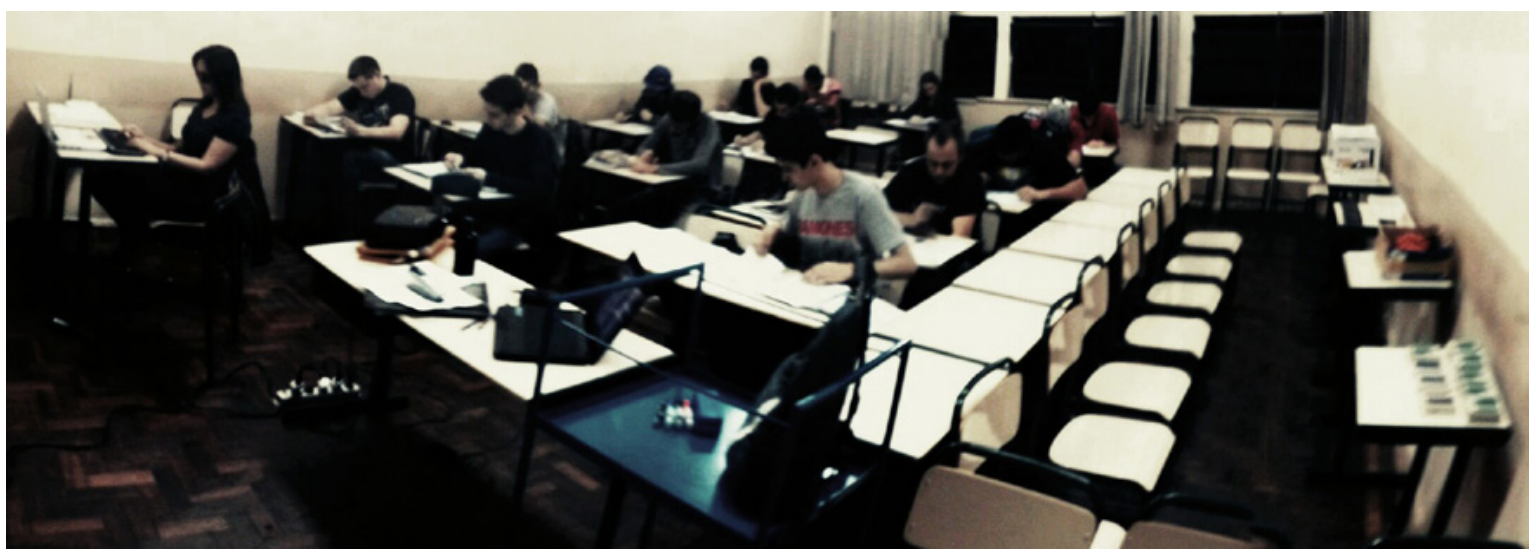

Fonte: capturado pelo autor

Questões de elevação da complexidade no planejamento, entretanto, representam apenas uma pequena parte da problemática. A criação de atividades diferenciadas requisita a preparação de materiais diferenciados e, quando utilizada tecnologia de informática, as atividades diferenciadas requerem a configuração e o teste de toda tecnologia envolvida para certificar-se de que éacessivel, além dos materiais que serão utilizados em conjunto com o programa leitor de telas instalado no computador. Considerando que existem diversas versões de programas de leitura de telas, cada uma com comandos diferentes, a pessoa cega deve, preferencialmente, estar apta a utilizar o programa de leitura de telas, ou adaptar-se ao programa disponibilizado. Caso exista mais de uma pessoa cega entre os alunos, pode ser necessária a utilização de mais de um programa de leitura de telas, e o professor deve conhecer as diferentes versões para que possa testar o material e as interfaces de configuração dos dispositivos, objetivando verificar compatibilidade. Quando o material didático/pedagógico não é fornecido, considerando a compatibilidade com programas leitores de tela, pode ser necessária a adaptação do material por parte do professor, incluindo a descrição textual das imagens, a diagramação em relevo dos diagramas e a reformatação das tabelas para um formato linear, além de um ritmo diferenciado para condução das atividades. 
O desafio é construir e pôr em prática, no ambiente escolar, uma pedagogia que consiga ser comum ou válida para todos os alunos da classe escolar, porém, capaz de atender os alunos cujas situações pessoais e características de aprendizagem requeiram uma pedagogia diferenciada. Tudo isto sem demarcações, preconceitos ou atitudes nutridoras dos indesejados estigmas. Ao contrário, pondo em andamento, na comunidade escolar, uma conscientização crescente dos direitos de cada um (BEYER, 2006, p. 76).

Atividades diferenciadas, quando lúdicas, também requisitam que diversos materiais sejam adquiridos, armazenados e organizados. Quando a instituição dispuser de recursos para preparação de material adaptado é necessário que o professor faça os devidos encaminhamentos e em tempo hábil. Por vezes o material adaptado pode ser de complexa construção, requisitando uma quantidade considerável de especificações para sua preparação, e todas as especificações devem ser entendidas e cumpridas pelas pessoas responsáveis por sua preparação na instituição. Caso a instituição não disponha de recursos (ex.: impressora em relevo) para preparação do material, o material deve ser preparado manualmente, o que demanda elaboração de lista de compras, o armazenar e o organizar de todos recursos, além da solicitação de compras de material quando estes estiverem em término, o que deve ser feito em tempo hábil para que seja realizado pelos setores encarregados da escola. Obviamente que todas estas considerações somente são passíveis de realização se o professor dispuser das competências e do tempo necessário para prever sua necessidade e tomar as providências para que sejam realizadas. Também é necessária estação para preparação do material adaptado, e limpeza após a construção de material que envolva colas e recortes, além de etiquetadora Braille que deve ser constantemente reabastecida com fitas específicas, objetivando permitir uma correspondência entre informações nos diagramas e informações repassadas via mídia de armazenamento. Procedimentos de backup também se fazem necessários, para quando o material em formato digital adaptado for preparado localmente, assim como para avaliações realizadas através da utilização de programa de editor de texto em conjunto com programa leitor de telas. Na Figura 5, tem-se uma avaliação somativa com diagramas em relevo, mídia portátil com questões a serem resolvidas em arquivo texto compativel com programa leitor de telas, computador com programa leitor de telas e um Roteador de Banda Larga residencial a ser manuseado. 
Figura 5 - Avaliação Adaptada

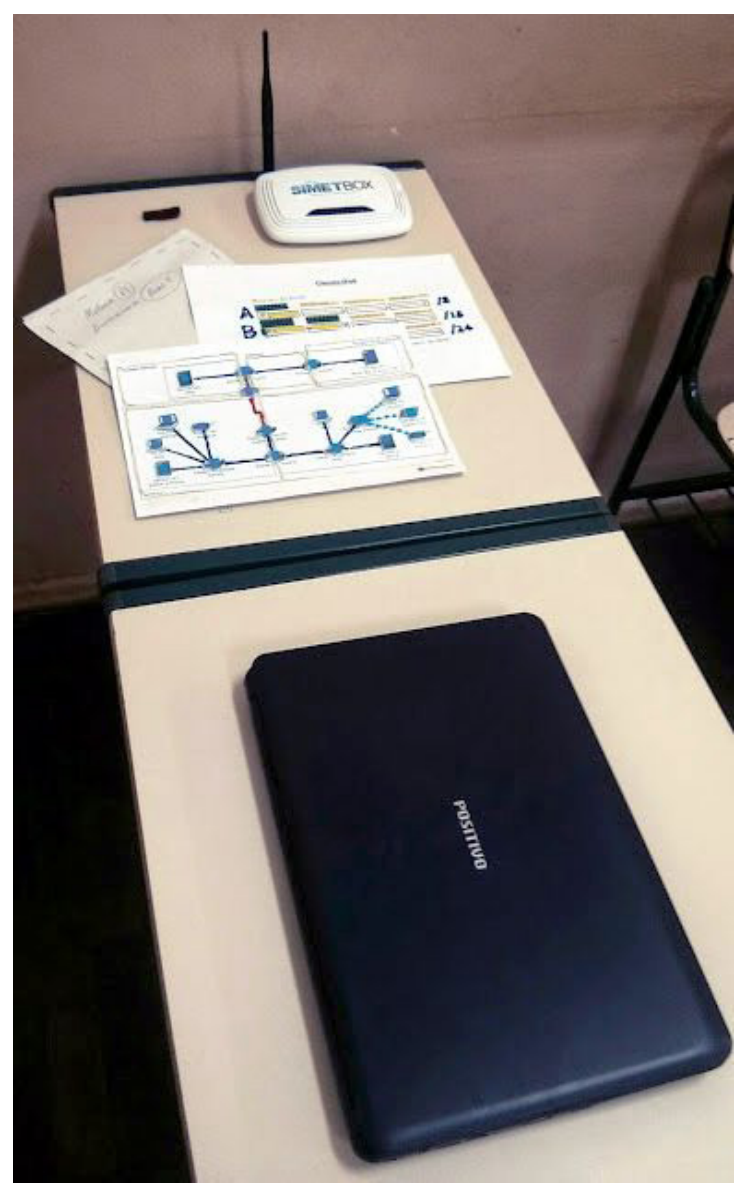

Fonte: capturado pelo autor

Em relação ao ambiente das aulas, pode ser necessário espaço extra para a disponibilização de material adaptado e de computador com programa leitor de telas, assim como extensões e conectores elétricos, o que pode restringir as opções para uma pessoa cega ocupar durante as aulas. A escolha pelo local da aula também deve ser considerada, pois alguns recursos tecnológicos encontram-se somente em determinados laboratórios de informática, tornando necessário o agendamento de laboratórios específicos para a realização da aula, ou um meio para transportar os equipamentos (ex.: notebook, cabo de extensão, adaptadores elétricos, etc.) até o local onde a aula será realizada. Na Figura 6 temse um carrinho para transporte de recursos até a sala de aula. Obviamente que, além do planejamento, 


\section{CONHECIMENTO

da preparação e transporte dos recursos adaptados, é necessário o planejamento, a preparação e o transporte dos recursos comuns para os demais estudantes. Adaptações curriculares não são uma alternativa fácil de ser realizada, porém podem ser recomendadas principalmente para os casos em que as atividades práticas apresentarem grau muito elevado de periculosidade quando considerada execução por pessoa cega.

\section{Figura 6 - Transporte de Recursos}

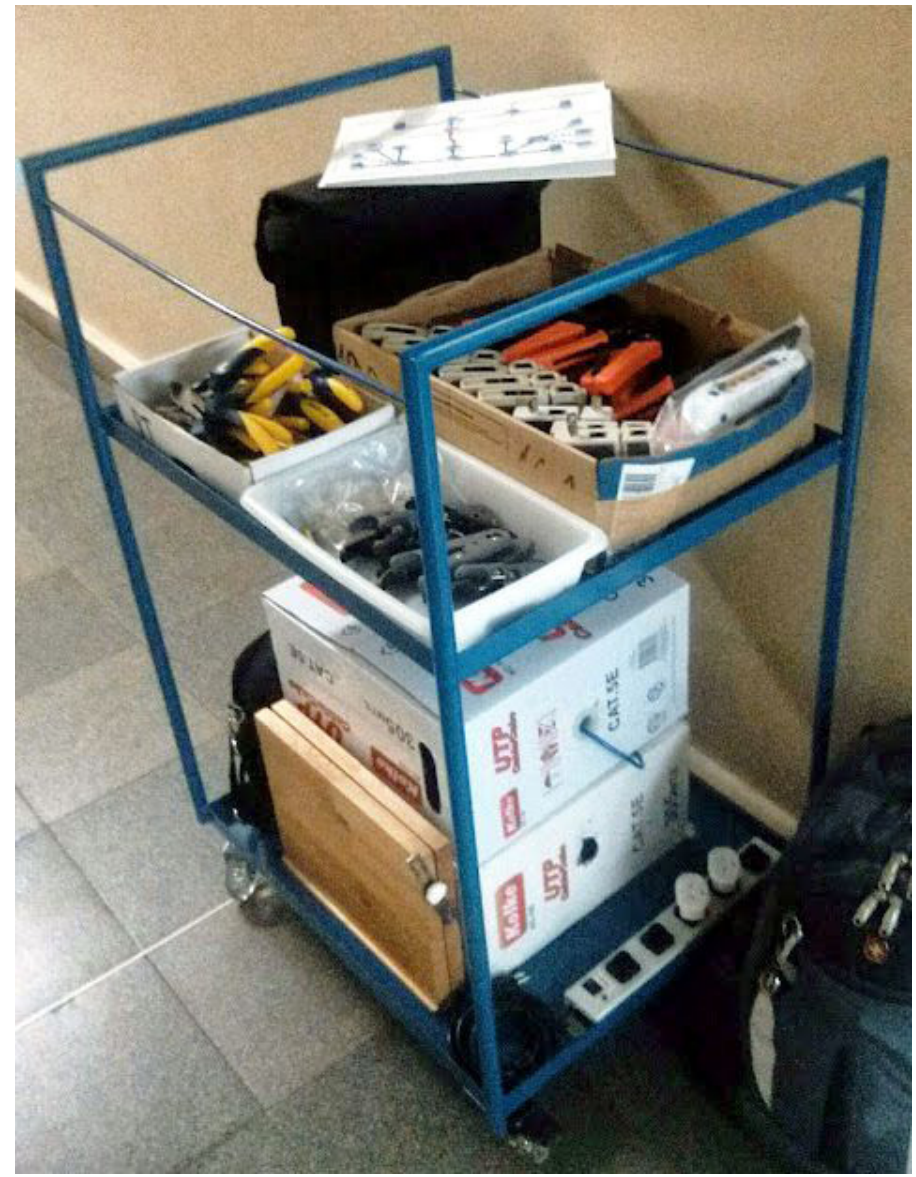

\section{Fonte: capturado pelo autor}

Quanto à utilização de alunos voluntários ou estagiários para ajudarem na elaboração de materiais adaptados ou para realizarem configuração de equipamentos, é necessário tempo para 
reuniões, sendo que tais períodos de trabalho devem ser coincidentes entre os envolvidos, e para isto é necessário que haja planejamento e carga horária disponibilizada. Outro fator referente à utilização de alunos e estagiários como auxiliares para tarefas, é o problema da alta rotatividade. Quando não existem profissionais permanentes e com disponibilidade para prover auxílio ao professor, uma possível consequência é a repetição de encontros para instruções, pois ao término da aprendizagem por parte de alunos e estagiários, novos alunos e estagiários apresentam-se, sendo necessário efetuar todas as tratativas novamente.

Anteriormente foram trabalhadas apenas as questões de âmbito de sala de aula e de laboratório, sendo que as dinâmicas em termos de chegada, intervalos e saída da instituição inclusiva também devem ser consideradas, por exemplo, através do fornecimento de alguma forma de acompanhamento para quando a pessoa cega não tiver apoio de colegas nestes momentos. Portanto, as relações de amizade dos estudantes, as questões de relacionamento com colegas, têm impacto nos recursos humanos necessários em termos de chegada na escola, intervalos e saídas. Pessoas com deficiências, assim como qualquer outro ser humano, podem ou não desenvolver relações de amizade e de confiança, e quando a escola não dispuser de infraestrutura acessível, como piso em relevo e indicações em Braille indicando locais, a pessoa com deficiência deve ser devidamente acompanhada.

\section{CONSIDERAÇÕES FINAIS}

Neste artigo foram apresentadas algumas considerações sobre as complexidades na inclusão de pessoa cega em disciplinas de infraestrutura tecnológica do sistema comum de educação. Entre as soluções para o provimento de tecnologia de informática mais acessível, encontra-se a possibilidade de criação de selo de acessibilidade para tecnologia de informática, assim como já existente para infraestrutura da construção civil. A utilização de selos para tecnologia de informática, entretanto, é mais complexa, pois envolve o processo de fabricação de tecnologia de enorme complexidade técnica, planejada e produzida em diferentes países, portanto, sendo necessário acordo em âmbito de ONU1 e $\mathrm{OMC}^{2}$ para produção de tecnologia mais acessível. A existência de selos de acessibilidade também facilita a definição de recursos a adquirir por parte de processos de licitação realizados por instituições de ensino e empresas. Em relação a páginas da Internet, devem ser elaboradas de acordo com regras para acessibilidade, e isto inclui as ferramentas de construção automatizadas de Websites, os sistemas

\footnotetext{
1 Organização das Nações Unidas.

2 Organização Mundial do Comércio.
} 
de EAD amplamente utilizados pelas instituições de ensino, assim como programas de computador, principalmente sistemas operacionais.

É porque o que está em causa não é a adoção do método A, ou do método B. O que está em causa é a necessidade de as escolas reconfigurarem suas práticas, para atenderem à diversidade. É urgente ajustar a gestão do espaço e do tempo escolar à medida de cada criança no ofício de aluno. [...] (PACHECO, 2012, p. 27).

A produção de material sendo fornecido em versão acessível a pessoas cegas por parte das editoras de material didático/pedagógico também pode facilitar o trabalho dos educadores no referente à produção de material adaptado. Já existem programas governamentais para produção de livros acessíveis, porém devem ser consideradas literaturas dos níveis de ensino técnico profissionalizante e não somente nível fundamental e médio.

A criação de infraestrutura de informática mais acessível e de materiais didático/pedagógicos sendo fornecidos pelas editoras considerando pessoas cegas, permitem uma aplicação do modelo de inclusão não somente na escola, mas na sociedade em geral, tornando possível que pessoas cegas possam adquirir tecnologia e recursos literários acessíveis sem a necessidade de estarem matriculadas em instituições de ensino. Selos de acessibilidade também facilitariam a aquisição de hardware e software mais acessíveis por parte de empresas que disponibilizam oportunidades de trabalho para pessoas com deficiências. Entretanto, a criação de tecnologia que permite que a pessoa cega leia materiais em formato comum - como a tecnologia de $\mathrm{OCR}^{3}$ com sintetização em áudio - pode compensar em parte pela inexistência de material acessível. Tais tecnologias, porém, são limitadas, não são confiáveis do ponto de vista de funcionamento, e por vezes requisitam revisões e correções no material gerado, não sendo ainda uma tecnologia capaz de solucionar a problemática da inexistência de literatura acessível em determinadas modalidades e niveis de ensino, ou mesmo substituir salas de recursos multifuncionais.

A formação docente também deve ser considerada, com aulas sobre tecnologia assistiva, estratégias pedagógicas, adaptações curriculares e atividades periculosas, sendo que cada tipo de deficiência e o contexto em que a inclusão é trabalhada requisita diferentes estratégias e recursos. Estágios em instituições especializadas também podem auxiliar na formação de profissionais da educação realmente preparados para prestar um bom atendimento nessas novas situações. A construção de equipes interdisciplinares nas escolas depende de professores preparados, com carga horária disponível, regimes

${ }^{3}$ Optical Character Recognition, em português: Reconhecimento Óptico de Caracteres. 
de dedicação exclusiva e baixa rotatividade dos servidores em geral, caso contrário o modelo de inclusão poderá estar fadado a inconstâncias, resultando em avanços e retrocessos.

[...] constatou-se que a formação inadequada dos educadores é uma das causas para não haver inclusão social, digital e principalmente escolar, pelo menos não de maneira satisfatória. A maioria das instituições responsáveis pela formação inicial dos educadores não contempla em seus currículos disciplinas relacionadas à inclusão e ao uso das Tecnologias de Informação e Comunicação (TIC) na educação. [...] (TERÇARIOL et al, 2005, p. 234).

Os requisitos para o ingresso de professores também devem considerar formações interdisciplinares, através da valorização de acadêmicos com formações específicas nessas áreas. Percebe-se, portanto, a necessidade de reformulação dos conteúdos trabalhados nos cursos de formação docente e nos requisitos para ingresso de professores para atuar nesse novo contexto trazido pelo modelo de diversidade cultural e inclusão social. Observa-se que as alterações em termos de recursos e práticas são diversas e complexas, sendo que todas estas complexidades devem ser consideradas quando elaboradas políticas públicas para a área da educação, para formação e contratação docente. É relevante, também, que cancelamentos ou abandonos de estudantes com deficiências sejam verificados por entidade/pessoa independente, objetivando evitar que instituições acabem por excluir a pessoa com deficiência, mesmo que não intencionalmente, através do mal atender e do maltratar, gerando, desta maneira, desligamentos de cursos através da prestação de serviços que podem ser aperfeiçoados através de avaliações e recomendações realizadas por profissionais especializados.

\section{REFERÊNCIAS}

AUGUSTIN, Ingrid. Modelos de Deficiência e suas Implicações na Educação Inclusiva. Universidade de Caxias do Sul. IX ANPED SUL. Seminário de Pesquisa em Educação da Região Sul. Anais... Caxias do Sul, 2012. Disponível em: <http://www.portalanpedsul.com.br/admin/uploads/2012/Educacao_Especial/ Trabalho/08_07_19_1427-7299-1-PB.pdf>. Acesso em: 21 jul. 2017.

BEYER, Hugo Otto. Da Integração Escolar à Educação Inclusiva: Implicações Pedagógicas. In: BAPTISTA, Claudio Roberto (Orgs). Inclusão e escolarização: múltiplas perspectivas. Porto Alegre, RS: Mediação, 2006. 73 p. 
BRASIL. Interdição parcial é mais legal. E a convenção sobre os direitos das pessoas com deficiência. Conselho Nacional do Ministério Público. Brasília: CNMP, 2014. 12 p. il. Disponível em: <http://www2. cnmp. mp. br/portal/images/Interdição_Parcial_11.06_WEB.pdf>. Acesso em: 21 jul. 2017.

BRASIL. Lei no 13.146, de 6 de julho de 2015. Disponivel em: <http://www.planalto.gov.br/ccivil_03/_ Ato2015-2018/2015/Lei/L13146.htm>. Acesso em: 20 mar. 2017.

CARVALHO, Rosita Edler. Escola inclusiva: a reorganização do trabalho pedagógico. Porto Alegre, RS: Mediação, 2014. 152 p.

LAPLANE, Adriana Lia Friszman de; BATISTA Cecília Guarnieri. O desenvolvimento e a aprendizagem da criança com deficiência visual. In: GOMES, Márcio; PACHECO, José. CORREIA, Secundino; FONSECA, Vitor da. et al. (Org.). Construindo as Trilhas para a Inclusão. Petrópolis, RJ: Vozes, 2012.

PACHECO. José. Berços da desigualdade. In: GOMES, Márcio (Org.). Construindo as Trilhas para a Inclusão. Petrópolis, RJ: Vozes, 2012.

PRODANOV, Cleber Cristiano; FREITAS, Ernani Cesar de. Metodologia do trabalho científico: métodos e técnicas da pesquisa e do trabalho acadêmico. 2. ed. Novo Hamburgo, RS: Feevale, 2013. 276 p. Disponivel em: <http://www.feevale.br/Comum/midias/8807f05a-14d0-4d5b-b1ad-1538f3aef538/Ebook\%20Metodologia\%20do\%20Trabalho\%20Cientifico.pdf>. Acesso em: 21 jul. 2017.

SENADO FEDERAL. Estrangeirismos grafados sem itálico ou aspas. Manual de Comunicação Secom, Senado Federal, 2012. Disponível em: <https://www12.senado.leg.br/manualdecomunicacao/redacaoe-estilo/estilo/estrangeirismos-grafados-sem-italico>. Acesso em: 28 abr. 2017.

TERÇARIOL, Adriana Aparecida de Lima; SOARES, Andréa Alves da Silva; GARCIA, Daniela Jordão et al. Construindo redes digitais de aprendizagem colaborativa. In: PELLANDA, Nize Maria Campos; SCHLÜNZEN, Elisa Tomoe Moriya; JUNIOR, Klaus Schlünzen. Inclusão Digital: Tecendo Redes Afetivas/ Cognitivas. Rio de Janeiro, RJ: DP\&A, 2005. 376 p.

ZANELLA, Andréa Vieira. Vygotsky: Contexto, contribuições à psicologia e o conceito de zona de desenvolvimento proximal. Itajaí: Ed. UNIVALI, 2001. 129 p. 